\title{
Mangelfolgeschäden im deutschen und ungarischen Recht
}

Grenzen der Haftung im Kauf- und Werkvertragsrecht - Kritik am Grundsatz der Totalreparation

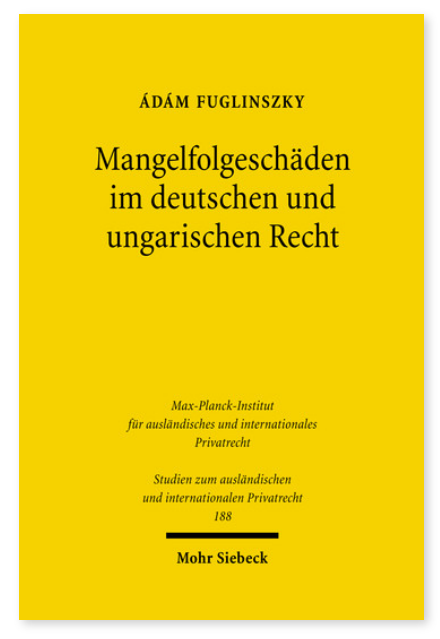

2007. XVII, 580 Seiten. StudIPR 188

ISBN 978-3-16-151373-2

DOI 10.1628/978-3-16-151373-2

eBook PDF 119,00€

ISBN 978-3-16-149421-5

fadengeheftete Broschur 119,00€
Die mangelhafte Leistung und die daraus entstandenen Schäden sind ein dauerhaftes Problem, das der Gesetzgeber glaubte, endlich auf eine sichere Grundlage gestellt zu haben. Ádám Fuglinszky hinterfragt dies kritisch und untersucht, ob der wünschenswerte Umfang des Schadensausgleichs für Folgeschäden im geltenden Recht gefunden wurde, bzw. ob dieser vielleicht mittels einer Vorhersehbarkeitsklausel - überhaupt gefunden werden kann. Die Schuldrechtsreform und die Neukodifizierung des ungarischen BGB, sowie die Natur der Folgeschadenproblematik liefern einen hinreichenden Anlass, bislang geltende Grundpositionen des Schadensrechts - darunter auch das Postulat der Totalreparation - grundsätzlich zu überdenken. Die Haftung für Mangelfolgeschäden steht im Brennpunkt der Bestrebungen des modernen Vertragrechts nach angemessener Risikoverteilung, nach Kalkulierbarkeit von Kosten und Nutzen einerseits, und der systemimmanenten Unsicherheit des Schadensrechts andererseits. Sowohl die Eintrittswahrscheinlichkeit als auch die Schadensbeträge sind kaum oder überhaupt nicht im Voraus kalkulierbar. Der Autor zeigt im unmittelbaren funktionalen Rechtsvergleich mit Ungarn eine neue Perspektive auf. Schwerpunkte werden bei der vertraglichen Haftungsbeschränkung im Individualvertrag und in AGB, bei den Zurechnungs- und Schadensberechnungsproblemen, bei dem Mitverschulden, sowie bei dem Vorteilsausgleich gesetzt.

Ádám Fuglinszky ist ordentlicher Professor am Lehrstuhl für Zivilrecht der Eötvös Loránd Universität, Budapest.
Jetzt bestellen:

https://mohrsiebeck.com/buch/mangelfolgeschaeden-im-deutschen-und-ungarischen-recht-9783161513732?no_cache=1 order@mohrsiebeck.com

Telefon: +49 (0)7071-923-17

Telefax: +49(0)7071-51104 